\title{
TCOM \\ Manga-based risk communication for the COVID-19 pandemic: a case study of storytelling that incorporates a cultural context
}

\section{Yasumasa Igarashi, Nozomi Mizushima and Hiromi M. Yokoyama}

\begin{abstract}
This article is about manga-based messaging for risk communication on COVID-19, describing the practice of collaboration between a group of experts and a popular manga artist. Collaborative storytelling through popular manga provides an effective discussion platform for diverse experts in various specialties, ages, and genders to discuss a topic in a short time. These "stories" can integrate social meaning, legitimacy, and a local context into scientific messages. They also provide the public with a deeper understanding of the messages through the characters and their "real-life" situations, as long as the messages remain consistent with the worldview of the original work.
\end{abstract}

Keywords

DOI

Introduction
Risk communication; Scholarly communication; Visual communication

https://doi.org/10.22323/2.19070802

Submitted: 30th June 2020

Accepted: 11th September 2020

Published: 14th December 2020

Risk communication is becoming more important, especially during the COVID-19 pandemic [Kasperson, 1986; Lundgren and McMakin, 2018]. Although COVID-19 is not well understood, lockdowns - rolled out worldwide - have been implemented and have changed people's lives and their values. To protect people, it is necessary to take action against what the World Health Organization has called an "infodemic," including fake news. At the same time, polite communication is required that is mindful of the culture of each country/region. This is because there are some cases, due to the cultural background, where the general public faces a hurdle in accepting safeguards, such as the use of masks.

The Japanese government closed schools nationwide on March 2 and issued an emergency declaration on April 16 asking people to stay at home. The emergency was lifted on May 25. There was no legal basis for the government to ask people to refrain from going out, and unlike a lockdown, government directives are not 
enforceable. However, at the end of March, several prominent comedians and actors died from COVID-19, so the fear and sadness of the Japanese people increased dramatically [Toriumi, Sakaki and Yoshida, 2020]. In addition, an announcement by an expert who appealed for an $80 \%$ reduction in personal contact had an enormous impact on people's behavior. ${ }^{1}$

The COVID-19 SciComm Forum was launched online at the end of March by Dr. Yokoyama, one of the authors. On June 11, 58 people participated in an online forum that included science communication practitioners and researchers, STS (science and technology studies) researchers, sociologists, physicians, and psychologists. The importance of communicating risk during emergencies as a group rather than as individuals has been recognized since the Great East Japan Earthquake in 2011 [Yokoyama, 2019]. Since March 2020, the forum has been an online platform for collecting information and exchanging opinions using MLs (mailing lists) and online chat (text) messages on a collaborative software app called Slack.

The forum has two missions. The first is to send useful information about COVID-19 out to society with SNSs (social networking services). The second mission is to provide the expert community with a platform using Slack and Zoom sessions for discussions on communication for crises, risk, and science. A collaboration with a popular manga artist is one of the projects of the first mission.

\section{Storytelling and Manga}

Before describing this project, we will explain the framework of this paper, and the background of manga (Japanese comics for both children and adults).

Storytelling, an effective method for scientific communication, has been used not only for a general audience, but also among scientific communication experts and practitioners [Riedlinger et al., 2019]. Combining cultural and scientific understanding is done through co-creation of the story among the manga artist and the science experts. The goal is to improve the effectiveness of science communication. In this paper, we report on discussions among various members of the SciComm Forum, among experts with different academic backgrounds, and between experts and the manga artist, as we collected this information for later publication. The risk communication process that has been organized and the product that will be distributed are reflexively examined by considering the cultural context and background in Japan.

Comics have been used as a visual storytelling medium for scientific communication [Farinella, 2018; Joubert, Davis and Metcalfe, 2019]. Storytelling can be used to communicate science to address various objectives: from raising awareness to critical deliberations on science. However, more importantly, comics can provide nuanced narratives that go beyond presenting facts and evidence, in this way helping audiences to process and recall new scientific information [ElShafie, 2018]. For example, the urine test analogy, used for explaining the use of

\footnotetext{
${ }^{1}$ https:/ / www.sciencemag.org/news/2020/04/did-japan-miss-its-chance-keep-coronaviruscheck, accessed on 18 August 2020.
} 
masks in English-speaking countries, is an example of this type of visual storytelling. ${ }^{2}$

Manga as a form of storytelling is spreading all over the world. It is one of the kinds of comic book developed in Japan after World War II, and has been deeply rooted in Japanese culture over a wide range of generations. Moreover, as manga is an expansive medium where personal identities and group cultures are expressed and developed [Pasfield-Neofitou, 2016], a particular manga can be an especially effective means of storytelling in Japan for individuals or groups who identify themselves with the world being illustrated and the characters in the manga. However, although science communication using comics is relatively common in Japan, few cases of risk communication during emergencies have been recorded [Watanabe, 2017].

In this practice insight, we explore, by employing a storytelling approach, the potential of manga for risk communication following a disaster. We used retrospective auto-ethnography, based on our own observations, experiences, and related documents, including texts and images that were posted on our Slack workspace, e-mails between a member of the experts group and the manga creator, as well as statistics related to SNS. First, we explain Chihayafuru, the manga series that we collaborated on, and how this collaborative project began. Next, we show several examples of manga-based messages, then analyze the development process and responses from the reading public within a cultural and localized context. Finally, we provide insights for further research and practices.

Based on this background, our research question as practice insight is:

Research question. What is needed for the storytelling approach to work effectively for risk communication in a crisis?

Outline of the

Chihayafuru manga and the project

\section{Background of the Chihayafuru manga}

Members of the SciComm Forum communicated about COVID-19 with popular manga artist/writer Yuki Suetsugu. She is the artist behind Chihayafuru, a popular serial manga that began in December 2007 with the theme of a Japanese competition called karuta, and boasts a cumulative circulation of 24 million. ${ }^{3}$

Karuta, a traditional card game or "mind sport" that requires memory, concentration, and physical fitness, is based on classical Japanese literature. People compete for the fastest taking of a card with tag from a classical Japanese poetry anthology (Hyakunin Isshu). Also, as emphasized in Suetsugu's work, unlike general sports, men and women often compete in the same tournament, and though Chihayafuru is a manga primarily for girls (known as shoujo manga), there are many fans regardless of gender.

\footnotetext{
${ }^{2}$ https: / / www.truthorfiction.com/wear-your-mask-the-urine-test-analogy-meme/, accessed on 29 June 2020.

${ }^{3}$ Ranking of all-time circulation of manga on Manga Zenkan DotCom (Japanese) website https:/ / www.mangazenkan.com/ranking/books-circulation.html, accessed on 29 June 2020.
} 
The Chihayafuru series is published in BE-LOVE, a magazine targeting women in their thirties and forties (a type of manga known as josei [Pasfield-Neofitou, 2016] ). There are also many young fans, including teenagers, due in part to the success of a TV anime series and a live-action movie series in which many popular young actors appeared. Chihayafuru has succeeded in gaining a wide fan base for both genders and various age groups. Moreover, set in typical modern Japanese school life, Chihayafuru portrays ordinary young people who are passionate about karuta, as well as experienced players, their parents and teachers, with the characters' team spirit and concern for each other as the main themes. Consequently, it seemed possible for a wide range of age groups to identify with certain characters, and for those characters to naturally send out messages on preventing the spread of a pandemic that required social solidarity and consideration for others. Therefore, due to its wide appeal and worldview, the members of the COVID-19 SciComm Forum thought that Chihayafuru would be suitable as a collaboration partner for distributing information on COVID-19.

\section{Flow of the production and dissemination of illustrations}

When starting this project, it was confirmed that Suetsugu had the final right to decide what kind of work to draw. Messaging that borrows the characters of a work with many fans is extremely effective, but if the behavior of the characters in the production (illustrations) is different from the worldview (perception) of the work, it not only dilutes the effect of the message, but a work that should be cherished is harmed, and fans would be put off. The top priorities were to respect the integrity of the work and to confirm the artist's intention for these collaborations.

Mindful of those two priorities, the work production process began. First, two of the authors opened a Slack thread named Collaboration with \# Yuki Suetsugu in the COVID-19 SciComm Forum, and invited members to participate. Three STS researchers, one physician, one freelance science communicator, and two science communicators from a research institute and a university participated using Slack. They were joined by several of the authors (one sociologist, two STS researchers). In this online thread, we discussed infectious disease control, concluding that it takes at least two weeks, considering how long the magna production would take. We then picked four or five themes for possible illustrations.

Next, the members discussed the specific images or the concrete design of how the Chihayafuru characters could appear for each theme and the kind of ideas they could express. Multiple designs were proposed for each illustration theme.

Developing proposals for the concrete design was a necessary step to convey what the SciComm Forum was asking Suetsugu to draw for each theme. Fortunately, there were several enthusiastic Chihayafuru fans among the members of the SciComm Forum, so discussions on the concrete design image were lively.

After that, one of the authors, Igarashi, told Suetsugu about the concrete images that the members had come up with after the discussions and requested their production. From the proposed themes, Suetsugu picked out what to actually draw, made several original drafts of the illustrations, and presented them to the SciComm Forum. All communications took the form of Igarashi contacting and communicating with Suetsugu on behalf of the forum. 
The original drafts of the illustrations proposed by Suetsugu were uploaded to the Slack thread of the SciComm Forum by Igarashi. Members then discussed how to present the risks and other considerations for COVID-19 to various viewers. The comments about the design and characters with their dialogue were also checked over the following two days. Based on those considerations, Igarashi asked Suetsugu for revisions, and she produced the final versions in color. The completed illustrations were presented on Slack for the SciComm Forum to see, and after checking with the members within a day or so, Igarashi told Suetsugu that it was okay to publish or that minor corrections were needed.

After these procedures, the works were posted on Twitter. As of June 14, at the time of the writing of this article, we have released eight manga-style message illustrations: four each on May 6 and May 18. One message, posted on May 6, contains an illustration of a fierce battle between the protagonist Chihaya and her rival Shinobu, as a "match location" to prevent the spread of infectious diseases (Figure 1). Aside from that one, the seven other illustrations that will be mentioned in detail in the next section are in a format that conveys what should be done through the depiction of the Chihayafuru characters spending their days during the pandemic.

The content of the message illustrations was confirmed by both the SciComm Forum and Suetsugu, then Suetsugu posted them on her Twitter account. Members of the SciComm Forum retweeted and shared Suetsugu's tweets on Twitter and Facebook.

In addition, Suetsugu not only sent out the illustrations, she also posted comments explaining the messages contained in each illustration. For example, in the one posted on May 6, depicting Shinobu immersing herself in an online karuta, with "even when away, we can still be connected" as the main copy line, the online comments describing Shinobu facing new technology were added, as shown in Figure 2 .

Co-creation process of the stories on risk communication
Figure 3 is a typical case of storytelling based on the world of manga and the characters' personalities. The theme of this illustration is the importance of keeping life as normal as possible to prevent mental and physical illnesses, even as schools are closed and people are staying at home all day. However, there was some concern among the experts about the top-down representation in the discussion. At that time, one of the members suggested that "Among the characters in Chihayafuru, Kana-chan (Kanade Oe) might be the one who is most adept at upholding the rules and regulations of life during the coronavirus pandemic," suggesting that "We should include her in the storyline." Another member responded, "I see, Kana-chan seems to do it, that's what I'm talking about!" The other members agreed. Then we built a storyline centered on Kanade: "In an online meeting, Chihaya and her colleagues are surprised to learn that one member, Kanade, is careful not to break from her regular routine, even wearing a kimono (traditional clothing)." Then, we shared this idea with the artist Suetsugu and a draft of the illustration was completed. In this case, the characters show a high level of empathy and the worldview of Chihayafuru to drive the story. 


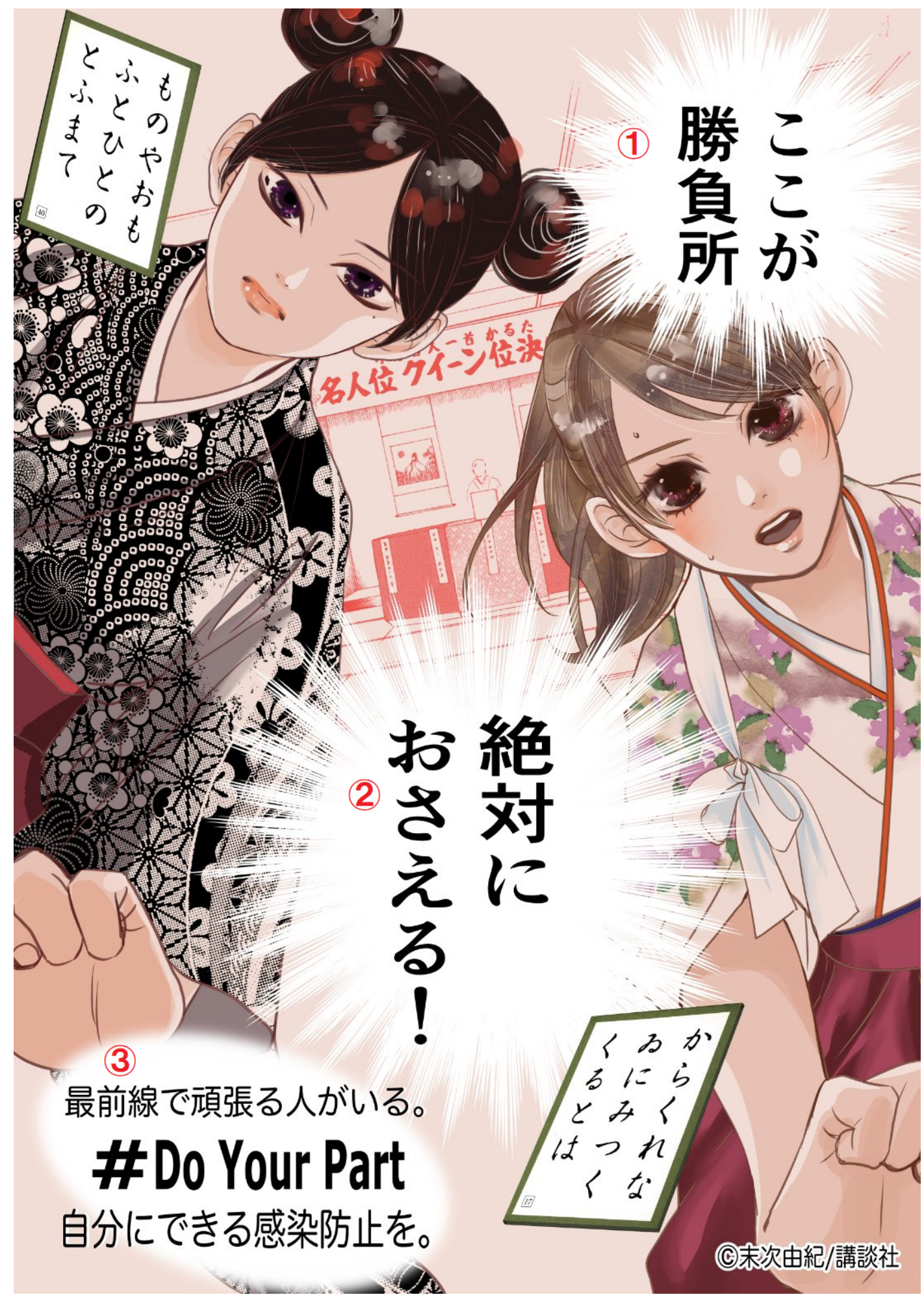

Figure 1. The first illustration from our collaboration posted on May 6, 2020. Translation: 1. This is the decisive moment! 2 . We'll definitely hold it off! 3 . There are people who do their best on the frontlines \# Do Your Part Let's prevent infection by yourself (This meta-message and hashtag can be found at the bottom of all following figures). 
一人でもかるたの練習を続けるであるう詩暢。でも実 は大会も好き。自分の強さ、札とのつながりを確認し たい思いは、詩暢をオンラインの戦場へ導く。そこは これまでとはまた違う強さが必要な世界。テクノロジ 一は私たちを救う。つなげる。うまく使っていこう。

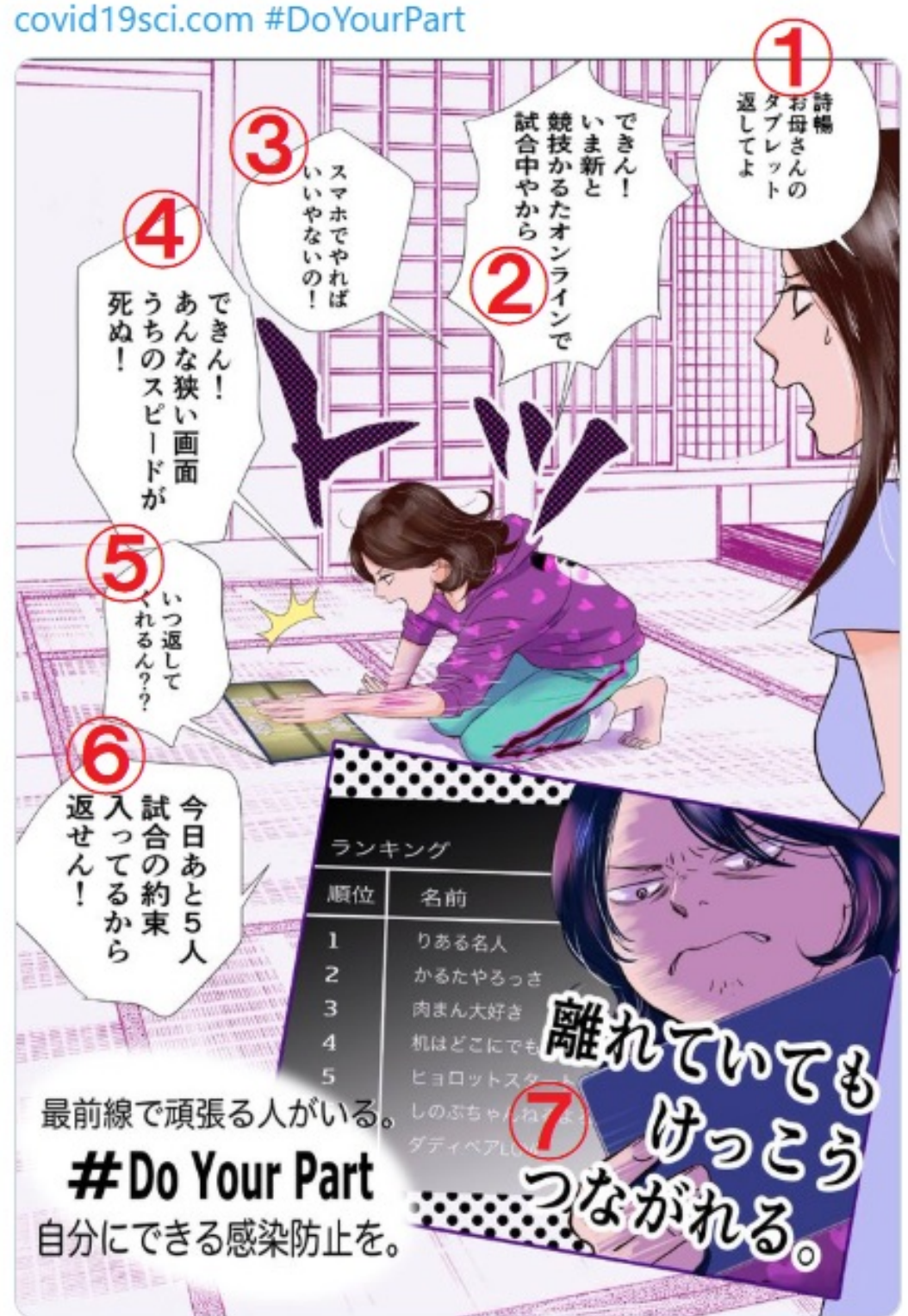

Figure 2. Tweet posted by Suetsugu with one of the illustrations on May 6, 2020. Translation: 0 . Shinobu will continue to practice karuta alone. But she really likes the competition. The desire to confirm her own strength and connection with the cards brings Shinobu to the online battlefield. There is a world that now requires a different kind of strength. Technology can save us. Connect. Let's use this well. 1. Shinobu, give me back my tablet! 2. I can't! I am playing a competitive karuta match online against Arata right now. 3. You could just use your smartphone! 4 . I can't! Its small display will kill my speed! 5. When are you going to return it to me then? 6. I promised five other people a match today, so I can't return it! 7. Even when away, we can still be connected. 


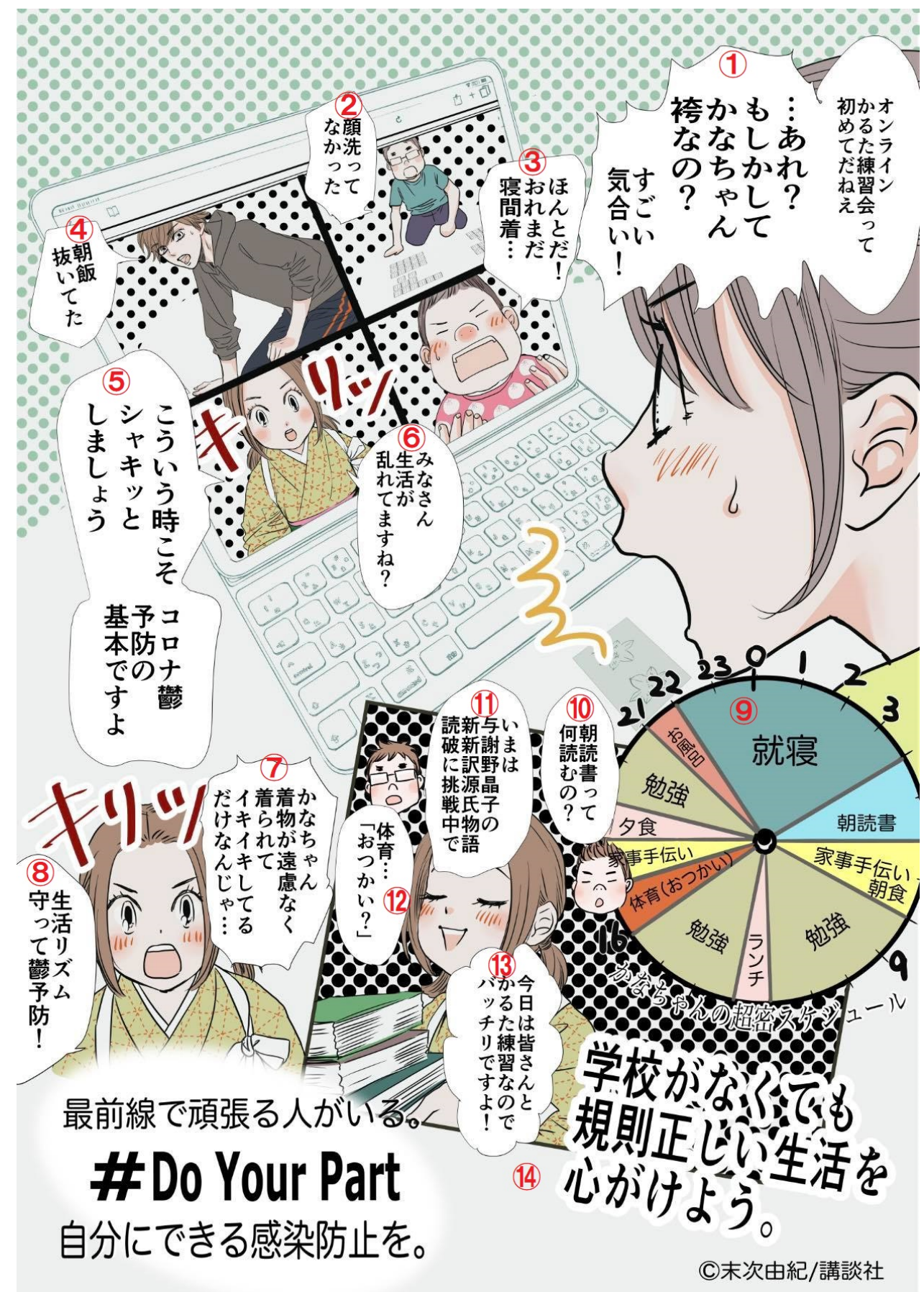

Figure 3. Illustration focusing on one character's personality. Translation: 1. This is our first online practice session. Are you wearing a hakama, Kana? A lot of spirit! 2. I noticed I didn't wash my face. 3. Really! I'm still in my pajamas... 4. I didn't have breakfast. 5. It's times to straighten up. It is the key to preventing corona depression. 6. You are all leading a disorderly life, aren't you? 7. Kana, you can wear a kimono without restraint and just look so lively. 8. Keeping life ordinary and routine to preventing corona depression! 9. Kana's super-tight schedule: 22-4 Going to bed, 4-6 Morning reading, 6-8 Helping with household chores and breakfast, 8-12 Study, 12-13 Lunch, 13-16 Study, 16-17 Exercise (going to supermarket), 17-18 Helping with household chores, 18-19 Dinner, 19-21 Study, 21-22 Taking a bath. 10. What do you read in the morning? 11. I'm trying a new-new translation of The Tale of Genji by Akiko Yosano. 12. Exercise... “Going to supermarket?". 13. Today, it's perfect because I have karuta practice with you all! 14. Try to have a regular life, even when schools are closed. 
In a tweet that accompanied this illustration, Suetsugu wrote a comment: "Kanade is the one who keeps doing this alone, even if she doesn't have school." She knows the readers (including us) can easily imagine Kanade's behavior if a pandemic were to strike. Kanade proudly says in the illustration, "It's times to straighten up," "Keeping life ordinary and routine is the key to preventing coronavirus depression!" These lines seem very preachy. However, when she says it, the message sounds convincing. In fact, audience responses included comments such as "Kana-chan, that's great!" or "I need to follow Kana-chan's example," showing a high level of empathy for the illustration and thus, the effectiveness of message sharing.

Manga-based scientific storytelling can tackle current, real-world problems by overlapping with real-life situations. In another example (Figure 4), Chihaya is crying over the cancellation of the Karuta High School Championship. In fact, that tournament, in the real world, was cancelled this year. Reality and the world of comics are in synch. Therefore, the reader "knows" in advance that Chihaya will be sadder than anyone else about the cancellation of the tournament. Therefore, the reader considers how her family should treat the heartbroken Chihaya and empower her within the "new normal." This social context might create deep empathy and awareness among students and their families in the same situation. Because Chihayafuru is a realistic work, it gives readers the sense that we are living in the same world as Chihaya and the other characters.

\section{Co-creation process focusing} on specific topics

\section{(a) Gender consideration and "self-restraint"}

In Japanese culture, there is relatively low awareness of gender equality. Men in Japan spend less time on housework and childcare than almost anywhere else in the world [Gender Equality Bureau, 2020]. ${ }^{4}$ It was pointed out that due to the COVID-19 pandemic, schools and nursery schools were closed, work at home was recommended, and the amount of housework and childcare increased only for women, making it difficult to do office work at home. ${ }^{5}$ Moreover, some messages issued by Japanese experts and governments regarding COVID-19 were singled out as being sexist.

In Suetsugu's manga illustrations, the gender issue was discussed when a scene was proposed showing Chihaya (female) going to the park to play with three children of the respected karuta player Haruka (female). The production process for one illustration is shown in Figure 5, Chihaya has been replaced by Akihiro (male), who is playing with his brother and his cousins.

This illustration, announced on May 18, had the most difficult ideas to convey, and it was feared that the theme would be controversial. In Japan, an emergency

\footnotetext{
${ }^{4}$ The government brochure “Women and Men in Japan 2020," p. 12, published by the Gender Equality Bureau, Cabinet Office for the latest statistics,

http:/ / www.gender.go.jp/english_contents/pr_act/pub/pamphlet/women-and-men20/pdf/14.pdf, accessed on 11 June 2020.

5 "The 'Stay Home' plan taking a toll on overburdened, lonely mothers," Asahi Shimbun, May 9, 2020, http:/ / www.asahi.com/ajw / articles/13334300, accessed on 11 June 2020., "Stuck at Home, Men in Japan Learn to Help. Will It Last?" The New York Times, May 16, 2020,

https:/ / www.nytimes.com/2020/05/16/world/asia/coronavirus-japan-household-work.html, accessed on 11 June 2020.
} 


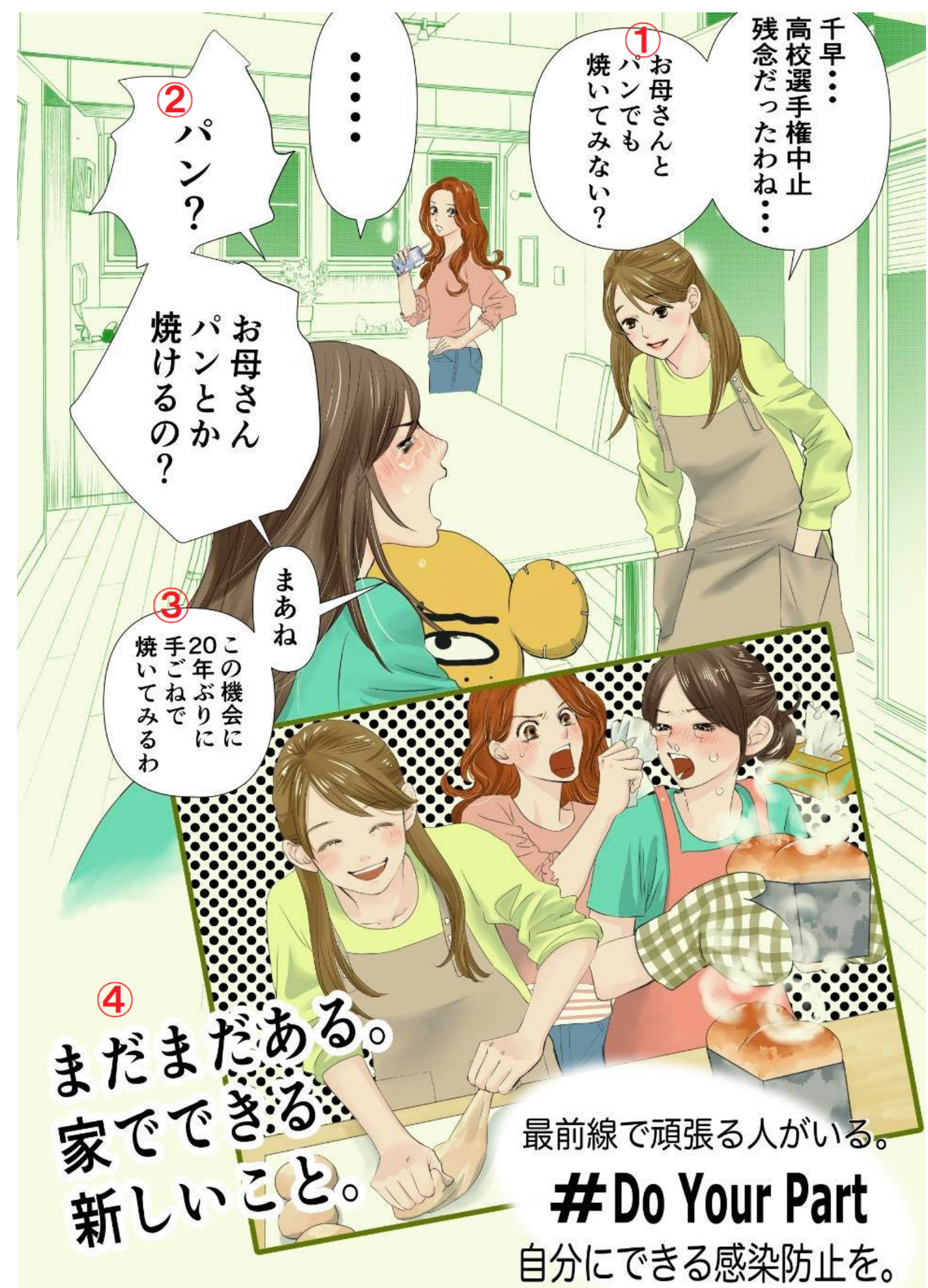

Figure 4. Illustration focusing on the main character's personality. Translation: 1. Chihaya... it's a shame that the high school championship got cancelled... Shall we bake some bread together instead? 2. Bread? You know how to bake bread, Mom? 3. I guess. It's been 20 years now, but I'll take this opportunity to make it from scratch. 4. They are still many new things you can do while at home. 


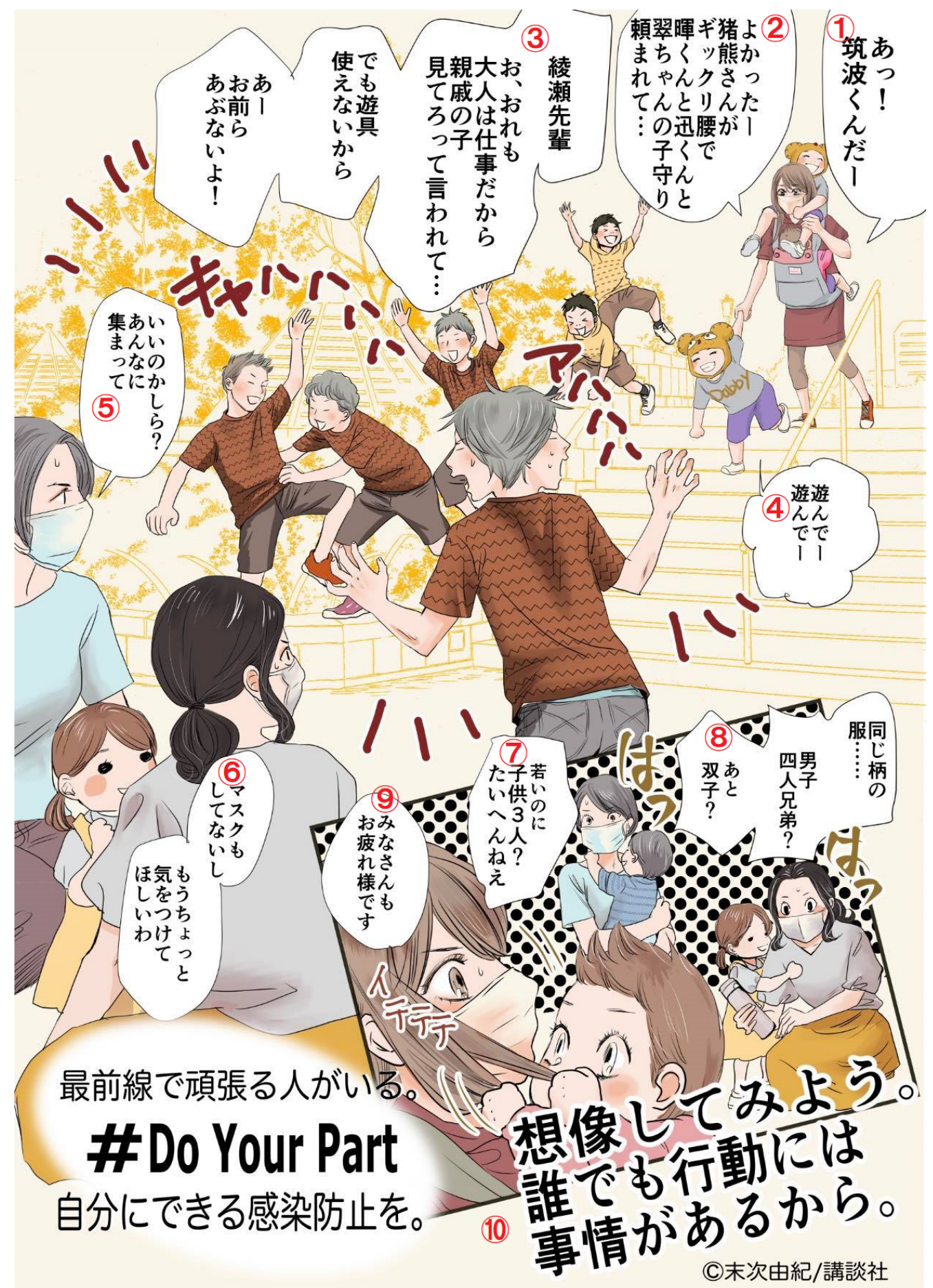

Figure 5. Illustration asking readers to imagine the entangled situation of others. Translation: 1. Oh, Tsukuba! 2. I was asked to babysit Aki, Jin, and Midori because Ms. Inokuma has a sore hip... 3. I was also told to take care of a relative's kids instead of their parents, who are working... But no playground equipment is allowed...Ah! It's dangerous, you guys! 4. Play with me; play with me. 5. Is it okay to get together like that? 6. They're not even wearing masks... They should be more careful. 7. You're so young, but do you have three kids? That's tough. 8. Clothes of the same pattern... Four boys? And twins? 9. You are also doing hard work. 10. Imagine. Everyone has their own actions. 
declaration was announced by the government on April 7; people were requested to stay at home. However, some people were still visiting resorts and it was feared that ignoring instructions could result in divisions within society. This was frequently reported in the news. However, in Japan, requests to stay at home and to close businesses were not legally binding; there were no penalties. Even in this situation, however, many Japanese people and stores were under strong social pressure to provide services and entertainment. In contrast, some citizens and stores who resisted the social pressure to close were criticized on SNS and some "flaming" (posting strong insults) occurred, or in the worst cases, actual harassment.

This phenomenon has been called "self-restraint policing," and it is feared that divisions in society could result. Members of the SciComm Forum and Suetsugu were acutely aware of this problem. Therefore, it was necessary to send a message to society to encourage a certain degree of understanding among citizens and stores who did not practice self-restraint.

Several images were suggested by the SciComm Forum for portraying this subject. Among them, the scene in the park was adopted by Suetsugu. She added main copy to this illustration, saying, "Imagine. Everyone has their own actions." When discussing the proposed illustration, it was initially suggested in the SciComm Forum that Chihaya (female) might happen to meet Haruka (female) who was playing with three children in the park. However, it was pointed out that the design unconsciously reproduced the current situation where the burden of housework and childrearing is placed solely on women, as mentioned above. Therefore, a SciComm Forum member told Suetsugu about this theme and the image, and it was changed to Haruka (female) meets Akihiro, a male teammate with many younger brothers and cousins, and a stereotyped description was avoided.

This illustration was the most prominent among those that Suetsugu produced. On Twitter, comments showing sympathy for the message and RTs (retweets) with posts and comments stood out. For example, someone posting as "Childcare Mother" expressed deep appreciation, commenting, "I don't want to go out with my child, but I have to do it." In Japan, the social norm that mothers take care of children is still strong. In the illustration, the double burden of self-restraint was highlighted by the counterstereotype of "a man who plays with a child in the park" while explaining the reason for the action. This manga showed the power of storytelling and a meaningful message.

\section{(b) \#Do Your Part as a Metamessage}

All the illustrations produced for this project have the hashtag \# Do Your Part at the bottom, and a related Twitter post from Suetsugu was attached, saying "Be sure to include the hashtags \# Save the world with imagination and \# Do Your Part."

A doctor's comments on the Internet inspired Suetsugu. In the words of Suetsugu herself, this is a key concept that has only one answer, "What kind of attitude do you have to have for anxiety about the future?" Suetsugu's strong intention to insert this message was proposed along with the original draft illustration. Moreover, the \# Do Your Part metamessage was compatible with the world of 
Chihayafuru, which emphasized themes of teamwork and each player's role and responsibility in karuta team competitions.

However, when the intention to incorporate this idea was communicated to the COVID-19 SciComm Forum, several members expressed concern about this hashtag and the Japanese message "Prevent spreading as much as possible" attached to the tag in the original draft. \# Do Your Part, meaning that all citizens should take responsibility for their own actions and prevent infections, is not a widespread idea in Japan, and it sounded slightly totalitarian and intrusive. For this reason, it was considered necessary to present this message with supplementary information in Japanese.

In addition, the attached message "Prevent spreading as much as possible" was a message that included Suetsugu's consideration for individual viewers, but there was the opinion that it sounded reluctant. Therefore, alternatives such as "What you can do now," "Do what you can do," and "One by one, everyone" were proposed to Suetsugu.

In response, Suetsugu added two Japanese messages, "There are people who do their best on the frontlines" and "Let's prevent infection by yourself" before and after \# Do Your Part. As a result, by adding them to all illustrations, this set of metamessages conveyed the significance of looking out for healthcare workers and fulfilling our responsibilities as citizens while considering the individuality of readers. This became the unified concept for the project.

\section{(c) The debate over the deficit model}

Here, we introduce an example that was proposed as a theme but later withdrawn. One of the members of the COVID-19 SciComm Forum is a media researcher involved in risk communication; he participates in a volunteer group of experts. Through him, we learned that the key members of the experts' group would like the public to understand the concepts R0 (R zero) and Rt (R time), which are useful in understanding the mechanism of the spread of infectious diseases.

In response to this concern, it was discussed in the forum whether it would be possible to make illustrations that explained medical terms to the public in an easy-to-understand way. The main characters in Chihayafuru include Harada, an elderly man who is a master on Chihaya's karuta team, who also has a medical practice in the suburbs of Tokyo, and Taichi, a high school boy who wants to take the exams to enter medical school. It seemed possible to explain difficult medical terms without deviating from the world of Chihayafuru using the form that Taichi would ask a question and Harada would answer it. On May 6, we also shared with Suetsugu a PowerPoint file prepared by the members explaining R0 and Rt in a way that was easy to understand.

Suetsugu expressed her willingness to tackle this challenge, but as she took on the difficult expression, she asked the SciComm Forum the obvious question, "What do you want to tell the public by explaining this concept?" With that question as the starting point, lively discussions took place. As a result, it was concluded that it was possible to promote a basic theoretical understanding and send a message about the necessary measures to take without using these terms. 
Further, even if there was a reasonable expression within the world of Chihayafuru, such as an explanation by the elderly male doctor, Harada, the expression had to be based on what is called the deficit model of science communication [Wynne, 1992; Wynne, 2006]. Igarashi told Suetsugu that he was withdrawing the request to introduce this theme. At that time, Igarashi explained that they were withdrawing the request, including communication issues such as the deficit model. This served as an opportunity to strengthen the relationship of trust for further collaboration.

Public response to the project
A finding, lessons, and what was learned
Suetsugu, a popular manga artist with 88,000 followers, announced a "new work" on the COVID-19 pandemic. It was well received by fans and many RTs (retweets) and comments were made in a short time. On May 6, Suetsugu posted 11 related tweets: a tweet that posted four illustrations in a batch; four tweets that introduced the illustrations one by one; five tweets on the creation process; and one tweet on the production or inside story. These tweets have been retweeted (RT) many times: 4,610 RTs in the 24 hours after being sent out. The tweet on May 6 had 2,403 RTs, 6,507 likes, and 623,491 impressions, and the tweet on May 18 had 2,508 RTs, 5,008 likes, and 750,577 impressions (confirmed on June 23).

On May 6, one of the leading Japanese Web magazines, Sirabee.com, covered in detail that Suetsugu had announced a work that highlighted infectious disease control. ${ }^{6}$ As a result, the manga illustrations gained wide recognition outside of SNSs (social networking services, or social media). Also, on June 7 , an English-language version of the four illustrations posted on May 6 was reposted from an account called "from Singapore and Canadian fans," and the remaining four illustrations in English were posted on July 19 from the same account. ${ }^{7}$ As a result, the message spread to some extent to non-Japanese-speaking fans.

Our research question was "What is needed for the storytelling approach to work effectively for risk communication in a crisis?" We found that storytelling using an existing manga or comic book series can successively enable discussions among experts and increase persuasiveness to readers due to the legitimacy based on the worldview of the manga and personal attributes of the characters. In particular, Japanese manga, with its emphasis on story, makes it easy for co-creation based on empathy among experts and with readers.

These types of stories usually take a long time to create. However, collaborating with a popular manga artist allowed us to create stories that could build a consensus in a heterogeneous group of experts and to quickly gain a deep understanding and empathy from a wide audience. This technique could be particularly useful for risk communication during an emergency, such as this pandemic, because the timing and reactions to different local situations is important.

In addition to those considerations, the selection of collaboration partners is also an important factor for the collaboration to go smoothly. In our case, the following

\footnotetext{
${ }^{6}$ https: / / sirabee.com/2020/05/06/20162319753/, accessed on 29 June 2020.

${ }^{7}$ https:/ / twitter.com/michixmame/status/1269437303832756224, accessed on 29 June 2020. https://twitter.com/michixmame/status/1284788562517356544, accessed on 31 August 2020.
} 
factors helped to facilitate our collaboration with the manga creator. First, Suetsugu contributed to the fund for promoting karuta based on Chihayafuru and there was high awareness of this social contribution. Second, local governments (Otsu City, Fuchu City, etc.) where the manga is set want to use Chihayafuru to promote their region, and Suetsugu supported this idea. Third, Suetsugu was very interested in promoting ways to prevent the spread of COVID-19.

Looking more closely at the process of co-creation (4. (a) to (c)), we learned several lessons for designing risk communication during a crisis.

(a) Gender awareness in Japan is very low. Specifically, women are unconsciously assumed to be raising Japan's children. Two STS (science and technology studies) gender experts were critical of the success of this illustration. At the same time, from the perspective of sociology, it was important, from an early stage, to be aware of problems such as self-restraint policing. During an emergency, the totalitarianism atmosphere becomes stronger in Japan, so there is a need for sociology to explain why people should be warned. All three generations are involved in child-raising and it is becoming easier to think about this situation in that way.

(b) Senior STS researchers in the COVID-19 SciComm Forum showed concern about totalitarianism. Japan's totalitarianism during World War II has been compared with the call for excessive unity following an emergency. Comments such as "There are people who do their best on the frontlines" and "Let's prevent infection by yourself" show that taking action by yourself is good for others. There was a proposal - based on a textbook for risk communication - to draw people's attention to this tendency.

(c) It was STS researchers who pointed out that explaining a mathematical model helps to deepen understanding, but when presented in an online manga, it easily becomes a model that includes social situations. This issue was so well known that it could be agreed on quickly.

Based on these experiences, we found the following lessons learned for risk communication during a crisis:

Lessons learned 1. It was important that the members of the forum had active discussions with the common goal of contributing to risk communication for COVID-19 countermeasures. For this reason, it became possible to quickly merge opinions.

Lessons learned 2. The wide range of ages of the forum members (from early 30s to late 60s), the gender balance, specialized fields, and interests in major subjects helped in multifaceted discussions. lives. For this reason, it is important to communicate risk in a contextual and meaningful way. In this project, manga-based "stories" definitely contributed to this point by integrating social meaning and legitimacy within the local context 
into a scientific message about risk communication, especially during internal discussions among project members. In other words, the characters and the world of a specific manga offer a shared image of an "imagined public" to the project members, who have different academic backgrounds and often perceive differing images of the public [Barnett et al., 2012; Solbu, 2018]. These stories, with the characters and their "real life" situations, also contributed to gaining a deeper understanding of messages by a wider audience through empathy.

To carry out risk communication in times of crisis, expert groups from different disciplines with a good knowledge of communication could work very well. In order to deal with the complicated reality, a diversified perspective was needed. We learned that it would be useful to form such a group in the event of an unexpected crisis.

Also, while manga-based scientific storytelling received a very good response, the most important thing is to have a group of professionals take care of the work and make the most of the characteristics of the story. It was fortunate to have an expert who had a trusting relationship with the author.

Finally, storytelling spilled over to a broader but limited audience than the original manga fans (readers). When using manga, it was important to note that these was a different audience from the original readers.

Acknowledgments First of all, we would like to express the deepest appreciation to Yuki SUETSUGU for providing a precious opportunity for the collaboration. This project would never be realized without her dedicated and passionate involvement. We are also grateful to the project members: Kohji HIRATA, Sae OCHI, Takayuki HONDA, Gensei ISHIMURA, and Seiko ISHIHARA-SHINEHA for their productive and insightful discussion and Tomoki SHIMIZU and Tomoaki YOSHITO for keeping us posted about this project through SNS. We are thankful to the other members in the COVID-19 SciComm Forum for their support and encouragement. This work was supported by the World Premier International Research Center Initiative (WPI), MEXT, Japan.

References

Barnett, J., Burningham, K., Walker, G. and Cass, N. (2012). 'Imagined publics and engagement around renewable energy technologies in the U.K.' Public Understanding of Science 21 (1), pp. 36-50. https://doi.org/10.1177/0963662510365663.

ElShafie, S. J. (2018). 'Making science meaningful for broad audiences through stories'. Integrative and Comparative Biology 58 (6), pp. 1213-1223. https://doi.org/10.1093/icb/icy103.

Farinella, M. (2018). 'The potential of comics in science communication'. JCOM 17 (01), Y01. https://doi .org/10.22323/2.17010401.

Gender Equality Bureau (2020). Women and men in Japan 2020. Japan: Cabinet Office, Government of Japan. URL: http://www.gender.go.jp/english_conten $\mathrm{ts} / \mathrm{pr}$ _act/pub/pamphlet/women-and-men20/index.html.

Joubert, M., Davis, L. and Metcalfe, J. (2019). 'Storytelling: the soul of science communication'. JCOM 18 (05), E. https: //doi .org/10.22323/2.18050501. 
Kasperson, R. E. (1986). 'Six propositions on public participation and their relevance for risk communication'. Risk Analysis 6 (3), pp. 275-281. https://doi.org/10.1111/j.1539-6924.1986.tb00219.x.

Lundgren, E. R. and McMakin, H. A., eds. (2018). Risk communication: a handbook for communicating environmental, safety and health risks. 6th ed. Hoboken, NJ, U.S.A.: IEE Press, John Wiley \& Sons, Inc. https://doi.org/10.1002/9781119456131.

Pasfield-Neofitou, S. (2016). 'Turning in to manga: cultural and communicative perspectives'. In: Manga vision: cultural and communicative perspectives. Ed. by S. Pasfield-Neofitou and C. Sell. Clayton, VIC, Australia: Monash University Publishing, pp. 1-12.

Riedlinger, M., Metcalfe, J., Baram-Tsabari, A., Entradas, M., Joubert, M. and Massarani, L. (2019). 'Telling stories to build collaboration between science communication scholars and practitioners'. JCOM 18 (05), N01. https://doi.org/10.22323/2.18050801.

Solbu, G. (2018). 'The physiology of imagined publics: from a deficit to an ambivalence model'. Science E Technology Studies 31 (2), pp. 39-54. https://doi.org/10.23987/sts.60908.

Toriumi, F., Sakaki, T. and Yoshida, M. (2020). 'Social emotions under the spread of COVID-19 using social media'. Transactions of the Japanese Society for Artificial Intelligence 35 (4), F-K45_1-7. https://doi.org/10.1527/tjsai.f-k45.

Watanabe, M. (2017). 'From top-down to bottom-up: a short history of science communication policy in Japan'. JCOM 16 (03), Y01. URL: https://jcom.sissa.it/archive/16/03/JCOM_1603_2017_Y01.

Wynne, B. (1992). 'Misunderstood misunderstanding: social identities and public uptake of science'. Public Understanding of Science 1 (3), pp. 281-304. https://doi.org/10.1088/0963-6625/1/3/004.

- (2006). ‘Public Engagement as a Means of Restoring Public Trust in Science Hitting the Notes, but Missing the Music?' Community Genetics 9 (3), pp. 211-220. https://doi.org/10.1159/000092659.

Yokoyama, H. (2019). 'Proposal for group voice: going beyond the limits of one voice and making information provided by scientists available to the public in emergency situations'. In: Environmental contamination from the Fukushima nuclear disaster: dispersion, monitoring, mitigation and lessons learned. Ed. by T. Nakajima, T. Ohara, M. Uematsu and Y. Onda. Cambridge, U.K.: Cambridge University Press, pp. 271-277. https ://doi .org/10.1017/9781108574273.

Yasumasa Igarashi is associate professor at Graduate School of Graduate School of Business Sciences, Humanities and Social Sciences, the University of Tsukuba. E-mail: VYL03222@nifty.com.

Nozomi Mizushima is an assistant professor at School of Advanced Sciences, the Graduate University for Advanced Studies (SOKENDAI). Her research focuses on public participation in science, citizen science, and feminist STS.

E-mail: mizushima_nozomi@soken.ac.jp. 
Hiromi M. Yokoyama is professor at the Kavli Institute for the Physics and Mathematics of the Universe, the University of Tokyo. Her research interests are science communication and public policy. E-mail: hiromi.yokoyama@ipmu.jp.

How to cite

Igarashi, Y., Mizushima, N. and Yokoyama, H. M. (2020). 'Manga-based risk communication for the COVID-19 pandemic: a case study of storytelling that incorporates a cultural context'. JCOM $19(07)$, N02.

https://doi.org/10.22323/2.19070802. 